\title{
Design on Tester of Fruit Surface Friction
}

\author{
Lei Yang, Xin Song, Yancong Li, Huiyong Shan \\ College of Engineering and Technology, Tianjin Agricultural University, Tianjin, 300384, China
}

\begin{abstract}
This paper introduces the basic structure, operation and working principles of a fruit surface friction tester and the test of friction coefficient between Fuji apple and silica gel which shows that the accuracy of the testing result met the designed requirements.
\end{abstract}

\section{Keywords-fruit; surface friction coefficient; tester.}

\section{INTRODUCTION}

When fruits are picked, transported, processed or stored, contact between them and the surfaces of other materials or friction between themselves may cause mechanical damages to them, which would result in reduced effect of mechanical picking and fruit quality, so friction coefficient is a critical determinant. In addition, factors including fruit variety, maturity, pressure of surface bearing and preservation temperature will also affect the friction coefficient of fruit surface.

Therefore, determination of the coefficients of static friction and kinetic friction on fruit surface is very important for the design of machinery picking, storage and transportation equipment and the selection of fruit storage and transportation modes[1].

So far no existing test instrument could accurately test the friction on fruit surface, so it is necessary to break through the existing technology and develop a simply structured and easy-to-use fruit surface friction tester.

\section{BASIC STRUCTURE}

The friction tester is composed of base, linear slide rail, driving stage, driven stage, push-pull gauge and its driving unit as well as fruit clamping assembly (as shown in Figure 1). The upper surface of the test bed upper surface is horizontally parallel to and symmetric with the fixed linear slide rail on which the driving stage is installed and slide horizontally. The push-pull gauge is fixed on driving stage which drives the driven stage installed on the linear slide rail to move.

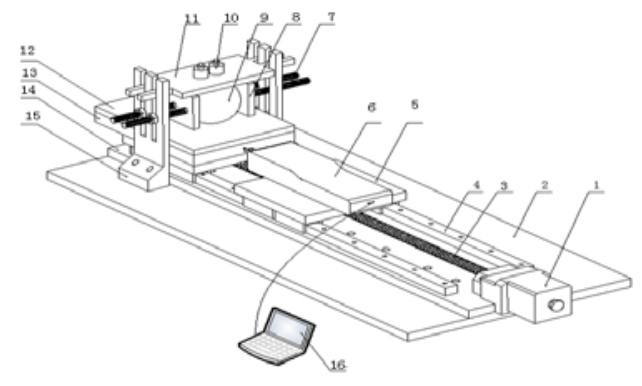

Figure 1 Friction tester

1. Stepper motor; 2. Base; 3. Ball screw; 4. Linear slider; 5. Driving stage; 6.Push-pull gauge; 7. Stud; 8. Clamping plate; 9. Sample; 10. Weight; 11. Load-bearing plate; 12. Friction sample; 13 Fixing plate; 14. Substrate; 15. Supporting frame; 16 . Computer

The driving unit is composed of ball screw and stepper motor. The ball screw is horizontally mounted under the driving stage and driven by the stepper motor which is installed at one end of the substrate.

The fruit clamping assembly is composed of supporting frame, clamping plate and stud. The symmetric supporting frames are mounted on the base outside the substrate. The upper parts of the two supporting frames are designed with a vertically symmetric $U$ groove in which two relatively sliding studs are mounted. The two facing ends of the studs are fixed onto the clamping plate used to clamp the object to be tested. After clamping the object to be tested, the clamping plate will be locked with nuts.

\section{OPERATION}

Fix the friction test piece on the fixing plate of driven stage and then put the object to be tested on it. Fix the object with clamping plates on both sides and lock the clamp with nuts. When the test requires the fruit to bear load, put the right weights on the load-bearing plate.

When the test begins, first start the stepper motor which will drive the ball screw to move and then the driving stage will make uniform rectilinear motion. The digital push-pull gauge fixed on driving stage and connected with fixing plate will drive the friction piece to move and produce a friction on fruit surface whose coefficient could be tested with the digital push-pull. When connected to a computer through data line, the digital push-pull gauge could accurately test the friction coefficient and pull-up curve. 


\section{WORKING PRINCIPLE}

The stepper motor will drive the driving stage to move and make the digital push-pull gauge make uniform rectilinear motion along the linear slide rail and give the driven stage a pull which will be gradually increased with the uniform rectilinear motion. The moment the digital pushpull gauge is about to pull the driven stage to move (when relative sliding between the fruit and the friction piece is about to occur), record the value of the pulling force F1[2].

According to the calculation formula of friction:

$$
\begin{aligned}
& F=\mu N=\mu\left(m_{\text {fuit }}+m_{\text {w eight }}\right) g \\
& \mu=F_{1} /\left(m_{\text {fruit }}+m_{\text {w eight }}\right) g
\end{aligned}
$$

Friction coefficient $\mu$ is static friction coefficient and pulling force $\mathrm{F} 1$ is the maximum static friction.

As the digital push-pull gauge continues to apply the pulling force on the friction piece, a relative sliding occurs between the fruit and the friction piece. After the gauge travels a certain distance, read the value of pulling force F2 which should be slightly smaller than the maximum static friction.

Also according to the calculation formula of friction, we can know that:

$$
\mu=F_{2} /\left(m_{\text {fruit }}+m_{\text {w eight }}\right) g
$$

Friction coefficient $\mu$ is kinetic friction coefficient.

During the movement, the pull-up curve which changes with time could be transmitted through digital push-pull gauge to and displayed on computer. The peak value of the pulling force is the maximum static friction used to calculate static friction coefficient. Later the puling force will be slightly reduced and become constant, and this constant value is the kinetic friction used to calculate kinetic friction coefficient.

\section{TeST EXAMPLe}

In this experiment, fresh and round Fuji apples without mechanical damage and disease or insect attack on surface are selected as the subjects to test the friction coefficient between apple and silica gel on this test bed. The selected apples are grouped and numbered and the horizontal movement speed of digital push-pull gauge is set to $1.5 \mathrm{~mm} / \mathrm{s}$. First, test the pulling force needed to move the force meter horizontally when no apple is loaded. Next, put the apple and prepared material plate on test bed to test the pulling force when relative sliding occurs between the fruit and the friction piece. Finally, take the average of the testing results and use the above formula to calculate the coefficient of friction between apple and silica gel.

TABLE I. Friction COEFFICIENT BETWEEN APPLE AND SiLICA GEL

\begin{tabular}{lccc}
\hline No. & $\begin{array}{c}\text { Without } \\
\text { apple }\end{array}$ & With apple & $\begin{array}{c}\text { Friction } \\
\text { Coefficient }\end{array}$ \\
\hline 1 & 16.0600 & 17.4900 & 0.6271 \\
2 & 16.3500 & 20.3000 & 1.7321 \\
3 & 18.0600 & 17.1200 & -0.4122 \\
4 & 15.8500 & 19.5700 & 1.6312 \\
5 & 16.0000 & 18.2000 & 0.9647 \\
6 & 16.1400 & 17.0900 & 0.4166 \\
7 & 16.1800 & 17.2600 & 0.4736 \\
8 & 15.0800 & 17.0300 & 0.8551 \\
9 & 16.1700 & 19.8000 & 1.5918 \\
10 & 16.2800 & 17.6500 & 0.6007 \\
Average value & 16.2170 & 18.1510 & 0.8481 \\
\hline
\end{tabular}

From the above table, we can conclude that the friction coefficient between apple and silica gel is 0.8481 , which is consistent with the value provided in reference document [3].

\section{CONCLUSIONS}

The utility model features simple structure and rational design. It can accurately measure the coefficients of static friction and kinetic friction between fruit surface and different friction pieces under different loads or at different driving speed, so as to provide a basis for the design of machinery picking, storage and transportation equipment and the selection of fruit storage and transportation modes.

\section{ACKNOWLEDGEMENTS}

The research work was supported by National Natural Science Foundation of China under Grant No. 51305299 and Tianjin Agricultural University Research \& Development Fund program under Grant No. 2012N02.

\section{REFERENCES}

[1] Altuntas E, Cangi R, Kaya C (2011) Physical and chemical properties of persimmon fruit. Int Agrophys 25:89-92

[2] Zhao JingYuan \& Wang ShuXian, Mechanics, Beijing: Higher Education Press, 1984.

[3] Qian ShaoMing, Research on Multi-fingered Robot Hand Based on the Flexible Pneumtatic Actuator FPA and its Application in Fruit Picking, Zhejiang University of Technology, 2012. 